\title{
AVALIAÇÃO DA COLONIZAÇÃO MICROBIOLÓGICA POR BACTÉRIAS \\ POTENCIALMENTE PATOGÊNICAS EM BARATAS BLATELLA GERMANICA CAPTURADAS EM EDIFÍCIO RESIDENCIAL DE UMA CIDADE DO INTERIOR PAULISTA
}

Ana Rita Paladino Tumitan, Júlio César da Silva

Universidade do Oeste Paulista - UNOESTE, Curso de Ciências Biológicas, Presidente Prudente, SP. e-mail: anarita@unoeste.br

\section{RESUMO}

Blattella germanica é uma barata domissanitária importante, desenvolvendo altas populações em restaurantes, residências, hospitais e locais de armazenamento de alimentos. Tendo em vista a importância desse inseto como vetor de microrganismos, este trabalho propôs a avaliar sua colonização por bactérias potencialmente patogênicas em amostras capturadas em edifício residencial de uma cidade do interior paulista. As amostras foram inoculadas em meios de cultura apropriados e identificadas por métodos convencionais. Foram identificadas: Enterobacter sp em $34 \%$ das amostras, Bacillus cereus em 12\%, Escherichia coli em 6\%, Staphylococcus aureus em 3\%, Baccilus subtilis em $3 \%$ e outras em $41 \%$. Considerando a presença de B. germanica nos apartamentos, transportando bactérias potencialmente patogênicas, é importante orientar os moradores sobre as medidas para controle desses insetos.

Palavras-chave: baratas, Escherichia coli, Bacillus cereus, Bacillus subtilis, Staphylococcus aureus.

\section{EVALUATION OF MICROBIOLOGICAL COLONISATION BY POTENTIALLY PATHOGENIC BACTERIA IN BLATELLA GERMANICA COCKROACHES CAPTURED IN RESIDENTIAL BUILDING OF SÃO PAULO STATE CITY}

\begin{abstract}
Blattella germanica is an important cockroach, developing high populations in restaurants, homes, hospitals and food storage locations. In view of its importance as a vector of potentially pathogenic microorganisms, this paper proposed to evaluate its colonization by potentially pathogenic bacteria in samples captured in residential building of São Paulo State city. The samples were inoculated in appropriate culture media and identified by conventional methods. Have been identified: Enterobacter sp in $34 \%$ of the samples, Bacillus cereus in $12 \%$, Escherichia coli in $6 \%$, Staphylococcus aureus in 3\%, Bacillus subtilis in 3\% and others at $41 \%$. Considering the presence of $B$. germanica in apartments, transporting potentially pathogenic bacteria, so it is important to advise residents about the measures for control of these insects.
\end{abstract}

Keywords: cockroaches, Escherichia coli, Bacillus cereus, Bacillus subtilis Staphylococcus aureus. 


\section{INTRODUÇÃO}

As baratas são reconhecidas como um importante vetor de infecções seja no ambiente hospitalar ou domiciliar, por serem carreadoras em potencial de microrganismos, levando-os na superfície do seu corpo para os materiais, equipamentos, utensílios e alimentos não contaminados ${ }^{1}$.

Blattella germanica (barata alemã) é uma das três espécies de baratas domissanitárias mais importantes, pois vem causando grande preocupação e prejuízos em países tropicais como o Brasil, desenvolvendo altas populações em restaurantes, residências, hospitais e locais de armazenamento de alimentos ${ }^{2}$.

Trabalhos realizados por Fotedar et al. ${ }^{3}$ e Elgderi et al. ${ }^{4}$ isolaram bactérias, parasitas e fungos de importância médica em baratas (Blattella germanica) coletadas em hospitais e domicílios, inclusive demonstraram a presença de bactérias resistentes a antimicrobianos.

Uma pesquisa publicada em 2002, realizada por pesquisadores do Instituto de Patologia Tropical e Saúde Pública da Universidade Federal de Goiânia coletou baratas das copas, do centro cirúrgico e das enfermarias, na lanchonete e no serviço de nutrição e dietética de hospital público. 0 resultado demonstrou crescimento bacteriano em 91 das 103 baratas analisadas. A distribuição e respectiva frequência dos microrganismos foram: $97 \%$ de fungos, $56 \%$ de enterobactérias, $18 \%$ de estafilococos coagulase negativos e 3\% de bacilos Gram negativos ${ }^{1}$.

Pai et al. ${ }^{5}$ em um estudo realizado em 90 hospitais em Taiwan verificou infestação em 42 deles. Foram isoladas 33 espécies de bactérias e 16 espécies de fungos de baratas da espécie Periplaneta americana. Esta espécie foi observada com maior frequência em áreas de apoio, e em áreas clínicas houve prevalência da espécie Blattella germanica, das quais foram isoladas 12 espécies de fungos e 23 espécies de bactérias, sendo nestas constatada a resistência bacteriana a ampicilina, cloranfenicol, tetraciclina e sulfametoxazol e trimetopim.

Segundo relatos colhidos de moradores de um edifício residencial situado em uma cidade do interior paulista, a $B$. germanica, ou "baratinha" como eles a conhecem, é presença constante em todos os cômodos dos apartamentos. É vista desde o banheiro até área de serviço, passando sobre cama, toalhas de banho, utensílios domésticos como talheres e panelas. Grandes infestações ocorrem comumente nos armários de cozinha, e há relatos de terem sido encontradas inclusive dentro de geladeiras, passando sobre alimentos, desde os compartimentos mais baixos até o congelador. 
Tendo em vista a frequência da presença de $B$. germanica no ambiente domiciliar e a importância desta, como vetor de microrganismos potencialmente patogênicos, este trabalho teve por objetivo avaliar sua colonização microbiológica por bactérias potencialmente patogênicas, por meio do isolamento e identificação das bactérias encontradas em sua superfície.

\section{MÉTODOS}

O local escolhido para coleta dos espécimes foi um edifício residencial, que conta com três andares de construção onde estão distribuídos 12 apartamentos com dois quartos, sala, cozinha, banheiro e área de serviço cada, e no térreo funcionam alguns seguimentos de comércio como perfumaria e vestuário.

Foram coletadas 21 amostras de todos os apartamentos, com exceção de um que estava desabitado.

As baratas (Blattella germanica), identificadas por seu tamanho (10 a 14 milímetros de comprimento), coloração e morfologia características (Figura 1) foram capturadas no ambiente domiciliar, nos períodos matutino e noturno, sendo as mesmas colocadas em frascos previamente limpos e desinfetados com álcool a 70\%, em seguida transferidas para um frasco estéril e encaminhadas ao laboratório de Microbiologia.

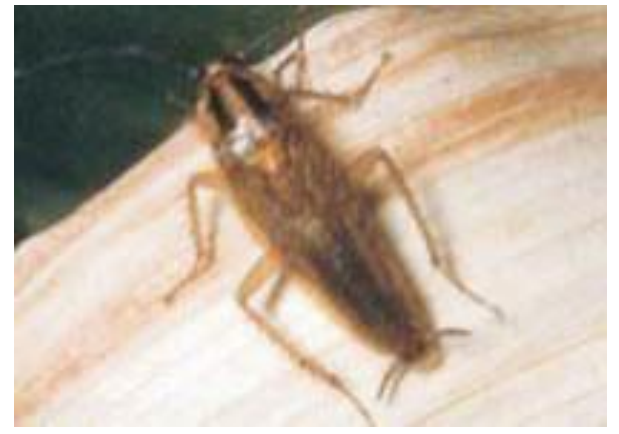

Figura 1. Blattella germânica (Von Zuben, 2006).

Foram utilizadas no estudo, as baratas que se encontravam íntegras e vivas, as quais foram imobilizadas a uma temperatura de $0^{\circ}$ C por um período de 15 minutos. As baratas imobilizadas foram retiradas dos frascos com o auxílio de pinça estéril, colocadas em tubos contendo cinco mililitros do meio de cultura caldo triptona de soja - TSB (OXOID LTD, Hampshire, England), que foram homogeneizados para que ocorresse desprendimento dos microrganismos presentes na superfície do inseto. Posteriormente as baratas foram retiradas dos meios e os mesmos foram incubados a $37{ }^{\circ} \mathrm{C}$ por 24 horas em estufa bacteriológica (Q316M, QUIMIS, Brasil). Após incubação, uma alçada $(0,01 \mathrm{ml})$ do meio TSB foi retirada e plaqueada para os meios ágar MüelerHinton (OXOID LTD, Hampshire, England), ágar Mac Conkey (OXOID LTD, Hampshire, England) e ágar manitol vermelho de fenol (OXOID LTD, Hampshire, England) que foram incubados a $37{ }^{\circ} \mathrm{C}$ por 24 horas em estufa 
bacteriológica (Q316M, QUIMIS, Brasil). O crescimento bacteriano foi analisado para contagem de colônias e as bactérias identificadas por meio de provas bioquímicas convencionais ${ }^{6}$.

\section{RESULTADOS}

Em todas as placas provenientes das amostras de $B$. germanica analisadas houve crescimento bacteriano abundante, sendo incontável o número de colônias. Em dez amostras foram isolados dois tipos de microrganismos e em uma amostra foram isolados três tipos. Foram encontrados bacilos Gram-negativos em quatorze amostras; bacilos Gram-positivos em dez amostras e cocos Gram-positivos em seis amostras.

Entre os bacilos Gram-negativos foram identificados Enterobacter sp em onze amostras, Escherichia coli em duas amostras, Pantoea agglomerans em duas amostras, Serratia sp em uma amostra e Pseudomonas sp em uma amostra. Entre os bacilos Grampositivos foram identificados Lactobacillus $\mathrm{sp}$ em seis amostras, Bacillus cereus em quatro amostras e Bacillus subtilis em uma amostra. Entre os cocos Gram-positivos foram identificados Staphylococcus epidermidis em quatro amostras, Staphylococcus aureus em uma amostra e Enterococcus sp em uma amostra.
A Tabela 1 mostra as bactérias identificadas em cada amostra analisada.

A Figura 2 mostra a frequência das bactérias isoladas de amostras obtidas de $B$. gemanica.

\section{DISCUSSÃO}

Em nosso estudo foram isolados bacilos Gram-negativos identificados como Enterobacter sp (em onze amostras), Escherichia coli (em duas amostras), Pantoea agglomerans (em duas amostras); Serratia sp (em uma amostra) e Pseudomonas sp (em uma amostra); bacilos Gram-positivos identificados como Lactobacillus sp (em seis amostras), Bacillus cereus (em quatro amostras) e Bacillus subtilis (em uma amostra); cocos Gram-positivos identificados como Staphylococcus epidermidis (em quatro amostras), Staphylococcus aureus (em uma amostra) e Enterococcus sp (em uma amostra). Algumas dessas bactérias (Escherichia coli, Bacillus cereus, Bacillus subtilis e Staphylococcus aureus) são potencialmente patogênicas e se contaminarem alimentos que posteriormente forem ingeridos pelas pessoas, podem ocasionar doenças de origem alimentar.

$$
\text { Fotedar et al. }{ }^{3} \text { e Elgderi et al. }{ }^{4}
$$
também isolaram bactérias de importância médica em baratas (B. germanica) coletadas em hospitais e em domicílios. 
Tabela 1. Bactérias identificadas em relação às amostras de $B$. gemanica coletadas em um edifício residencial de uma cidade do interior paulista.

\begin{tabular}{|c|c|c|}
\hline Amostra & Gram & Bactéria identificada \\
\hline $1 \mathrm{a}$ & BGP longos & Lactobacillus $\mathrm{sp}$ \\
\hline $1 b$ & $\begin{array}{l}\text { BGP longos } \\
\text { CGP }\end{array}$ & $\begin{array}{l}\text { Lactobacillus sp } \\
\text { Staphylococcus epidermidis }\end{array}$ \\
\hline $2 a$ & BGN & Enterobacter sp \\
\hline $2 b$ & CGP & Enterococcus sp \\
\hline $3 a$ & $\begin{array}{l}\text { BGN } \\
\text { BGP esporulados }\end{array}$ & $\begin{array}{l}\text { Serratia sp } \\
\text { Bacillus subtilis }\end{array}$ \\
\hline $3 b$ & $\begin{array}{l}\text { BGP esporulados } \\
\text { BGN }\end{array}$ & $\begin{array}{l}\text { Bacillus cereus } \\
\text { Enterobacter } s p\end{array}$ \\
\hline $4 a$ & $\begin{array}{l}\text { BGN } \\
\text { CGP }\end{array}$ & $\begin{array}{l}\text { Enterobacter sp } \\
\text { Staphylococcus epidermidis }\end{array}$ \\
\hline $4 \mathrm{~b}$ & BGP esporulados & Bacillus cereus \\
\hline $5 a$ & BGP esporulados BGN & $\begin{array}{l}\text { Bacillus cereus } \\
\text { Enterobacter } s p\end{array}$ \\
\hline $5 b$ & $\begin{array}{l}\text { BGN } \\
\text { BGP longos }\end{array}$ & $\begin{array}{l}\text { Enterobacter } s p \\
\text { Lactobacillus } s p\end{array}$ \\
\hline $6 a$ & $\begin{array}{l}\text { BGP longos } \\
\text { BGN }\end{array}$ & $\begin{array}{l}\text { Lactobacillus sp } \\
\text { Enterobacter sp }\end{array}$ \\
\hline $6 b$ & $\begin{array}{l}\text { BGN } \\
\text { CGP }\end{array}$ & $\begin{array}{l}\text { Escherichia coli } \\
\text { Staphylococcus aureus }\end{array}$ \\
\hline $7 a$ & CGP agrupados & Staphylococcus epidermidis \\
\hline $7 b$ & BGP longos & Lactobacillus sp \\
\hline $8 a$ & $\begin{array}{l}\text { BGN } \\
\text { CGP }\end{array}$ & $\begin{array}{l}\text { Enterobacter sp } \\
\text { Staphylococcus epidermidis }\end{array}$ \\
\hline $8 b$ & $B G N(A, B$ e $C)$ & Escherichia coli, Enterobacter sp e Pseudomonas sp \\
\hline $9 a$ & BGP esporulados & Bacillus cereus \\
\hline $9 b$ & $B G N(A$ e $B)$ & Enterobacter sp e Pantoea agglomerans \\
\hline $10 a$ & $\mathrm{BGN}$ & Enterobacter $s p$ \\
\hline $10 b$ & $\begin{array}{l}\text { BGP longos } \\
\text { BGN }\end{array}$ & $\begin{array}{l}\text { Lactobacillus sp } \\
\text { Pantoea agglomerans }\end{array}$ \\
\hline $11 a$ & BGN & Enterobacter sp \\
\hline
\end{tabular}

Legenda: BGN bacilos Gram-negativos, BGP bacilos Gram-positivos, CGP cocos Gram-positivos. 


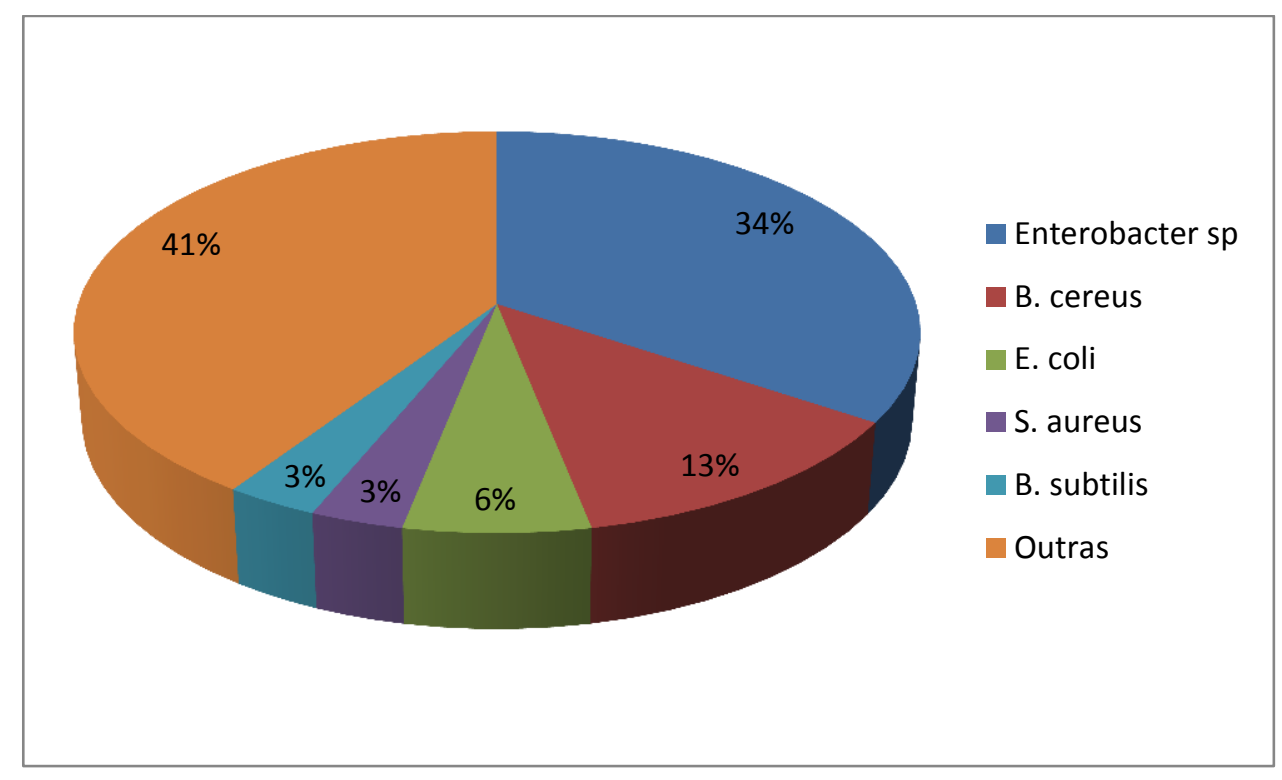

Figura 2. Frequência das bactérias isoladas de B. germanica coletadas em edifício residencial de uma cidade do interior paulista.

Em relação à frequência de bactérias isoladas nossos resultados são coerentes com os de Prado et al. ${ }^{1}$, que obtiveram maior frequência de enterobactérias em seus isolados de baratas (Periplaneta americana), sendo que as espécies de Enterobacter predominaram. Nossos resultados são ainda semelhantes aos de Elgderi et al. ${ }^{4}$, que encontraram predomínio de Enterobacter sp, Klebsiella sp, Citrobacter sp e Aeromonas sp em B. germanica de ambiente domiciliar.

Encontramos E. coli em $6 \%$ das amostras analisadas.

O grupo de bactérias denominadas coliformes, capazes de fermentar a lactose com produção de gás a $35{ }^{\circ} \mathrm{C}$, compreende 20 espécies, incluindo bactérias do trato gastrintestinal de humanos e de animais como E. coli, Enterobacter sp, Klebsiella sp,
Citrobacter sp entre outras, como também diversas bactérias não entéricas, como por exemplo, Aeromonas sp e Serratia sp. Nesse grupo, destacam-se os coliformes fecais ou termotolerantes que inclui Enterobacter sp, Klebsiella sp e Escherichia coli capazes de fermentar a lactose com produção de gás, a $44,5-45,5{ }^{\circ} \mathrm{C}^{7,8}$. E. coli é o mais importante indicador de contaminação fecal ${ }^{9}$.

Praticamente todos os alimentos de origem vegetal ou de origem animal que não tenham sido processados, podem veicular linhagens patogênicas de $E$. coli, desde que, em algum momento, tenham sido sujeitos a poluição fecal. Os principais e mais frequentes sintomas caracterizam- se pelo aparecimento de diarreias, febre e náuseas que, normalmente, aparecem 6 a 36 horas após a ingestão do alimento contaminado ${ }^{10}$. 
Nosso estudo isolou Bacillus cereus em $12 \%$ das amostras de $B$. gemanica.

A ingestão de alimentos mantidos em temperatura ambiente por longo tempo, depois de cozidos, permite a multiplicação de B. cereus $^{11}$.

O gênero Bacillus é composto por bacilos Gram-positivos aeróbios ou aneróbios facultativos, que produzem endosporos. As espécies desse gênero habitam solos, águas e pó aerotransportado, sendo que algumas espécies fazem parte da microbiota intestinal do homem e animais ${ }^{6}$.

Bacillus cereus é uma espécie de importância médica, associado com surtos de intoxicação alimentar, enfermidade caracterizada por vômitos, cólicas abdominais e diarreia. São conhecidas duas toxinas: uma toxina emética (termoestável) que causa vômito e uma enterotoxina (termolábel), responsável pela diarreia ${ }^{11}$.

Baccilus subtilis foi encontrado em uma das amostras analisadas (3\%).

Algumas cepas de $B$. subtilis foram isoladas de carneiro e frango relacionados a episódios de intoxicação alimentar. Estes microrganismos produzem uma toxina altamente termoestável a qual pode ser similar à toxina do tipo emético produzida pelo B. cereus $^{11}$.

Staphylococcus aureus foi identificado em uma amostra de B. germanica (3\%).

Staphylococcus sp estão presentes no ar, na poeira, em esgotos, água, leite, em superfícies e equipamentos, em humanos e animais $^{12}$. São bactérias Gram-positivas, imóveis, esféricas, agrupadas em massas irregulares em forma de cacho. Apresentam metabolismo respiratório e fermentativo atuando sobre carboidratos com produção de ácidos, sendo aeróbias e anaeróbias facultativas. Podem crescer em temperaturas entre 7 a $48{ }^{\circ} \mathrm{C}$, com um ótimo de 30 a $37{ }^{\circ} \mathrm{C}$. Staphylococcus aureus é um dos agentes patogênicos mais comuns, responsável infecções piogênicas e toxigênicas, inclusive surtos de intoxicação de origem alimentar ${ }^{13}$. A intoxicação é causada pela enterotoxina e caracterizada por vômito proeminente e diarreia aquosa não sanguinolenta ${ }^{14}$.

Considerando o fato de que as baratas B. germanica capturadas nos apartamentos carregam bactérias potencialmente patogênicas que podem contaminar alimentos e provocar danos à saúde humana, é importante orientar os moradores a respeito das medidas para controle desses insetos.

Segundo Von Zuben ${ }^{15}$, a aplicação de inseticidas nas áreas de abrigo do inseto e a adoção de medidas de saneamento do meio, como remover diariamente o lixo, eliminação dos abrigos, limpeza diária do fogão e embaixo da geladeira, limpeza periódica de ralos de cozinha, banheiro e área de serviço, 
conservação dos alimentos de modo a impedir o alcance das baratas, entre outras, propiciam um controle preventivo das baratas ou a diminuição da infestação, no caso de já se encontrarem no ambiente.

\section{CONFLITO DE INTERESSE}

Os autores declaram não haver qualquer potencial conflito de interesse que possa interferir na imparcialidade deste trabalho científico.

\section{REFERÊNCIAS}

1. Prado MA. Microrganismos isolados de baratas (Periplaneta americana) em um hospital público de grande porte da região Centro Oeste. Rev Eletrônica Enferm. 2002;4(1):61. Disponível em: http://www.revistas.ufg.br/index.php/fen

2. Mariconi FAM. As baratas. In: Mariconi FAM (Ed). Insetos invasores de residências. Piracicaba: FALQ, v.6, p.13-33, 1999.

3. Fotedar R, Shriniwas UB, Verna A. Cockroaches (Blatella germanica) as carriers of microorganisms of medical importance in hospitals. Epidemiol Infection. 1991;107:181187.

DOI: http://dx.doi.org/10.1017/S09502688000488 09

4. Elgderi RM, Ghenghesh KS, Berbash N. Carriage by the german cockroach (Blattella germanica) of multiple- antibiotic-resistant bacteria that are potentially pathogenic to humans, in hospitals and households in Tripoli, Libya. Ann Trop Med Parasitol 2006;100:55-62.

DOI: http://dx.doi.org/10.1179/136485906X78463
5. Pai HH, Chen WC, Peng CF. Cockroaches as potential vector of nosocomial infections. Infection Control Hosp Epidemiol 2004;25:979-984. DOI: http://dx.doi.org/10.1086/502330

6. Koneman EW, Allen SD, Woods GL. Diagnóstico microbiológico: texto e atlas colorido. 6.ed. Rio de Janeiro: Guanabara Koogan; 2008.

7. Hitchins AD, Hartman PA, Todd ECD. Compendium of methods for the microbiological examination of foods: Coliforms-Escherichia coli and its toxins. 3.ed. Washington: American Public Health Association; 1996.

8. Vanderzant C, Splittstoesser DF. Compendium of methods for microbiological examination of foods. 3.ed. Washington: American Public Health Association, 1996.

9. Silva N, Junqueira VCA, Silveira NFA. Manual de métodos de análise microbiológica de alimentos. São Paulo: Varela; 1997.

10. Santos GS. Microrganismos causadores de doenças de origem alimentar. Food Ingred Brasil. 2011;19:51-59.

11. CVE - Centro de Vigilância Epidemiológica. Manual das doenças transmitidas por alimentos - Bacillus cereus/intoxicação alimentar. Divisão de Doenças de Transmissão Hídrica e Alimentar, 2002.

12. CVE - Centro de Vigilância Epidemiológica Manual das doenças transmitidas por alimentos Staphylococcus aureus/intoxicação alimentar. Divisão de Doenças de Transmissão Hídrica e Alimentar, 2003.

13. Castro MM, laria ST. Staphylococcus aureus enterotoxigênico no vestíbulo nasal de manipuladores de alimentos em cozinhas 
de hospitais do município de João Pessoa, PB.

Rev Saúde Púb. 1984;18:235-254. DOI:

http://dx.doi.org/10.1590/S0034-

89101984000300005

14. Levinson W. Microbiologia Médica e Imunologia, 10.ed. Porto Alegre: Artmed editora; 2010.

15. Von Zuben APB. Manual de Controle Integrado de Pragas. Secretaria Municipal de Saúde de Campinas. [periódico eletrônico], 2006. Disponível em: http://www.campinas.sp.gov.br/sa/impresso s/adm/FO086.pdf

Recebido para publicação em 09/04/2014

Revisado em 21/01/2015

Aceito em 16/04/2015 